\title{
US specialty societies urged to disclose industry ties
}

Published at www.cmaj.ca on May 5

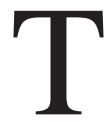
he United States Council of Medical Specialty Societies has unveiled a code of ethics that will ask member bodies to disclose all financial contributions from industry.

But the new Code for Interaction with Companies is entirely optional and falls short of setting either a cap or an outright ban on industry support.

While signatories are required to keep society administration and decision-making separate from their efforts to seek education grants, corporate sponsorships, charitable contributions, and research grants, there is no dollarand-cents limit on the amount of support industry may contribute to a society, so long as it is publicly reported.

"Our goal is to eliminate industry influence, not industry support. Setting an arbitrary amount of support is irrelevant if the nature of that support results in influence," says Dr. Norman Kahn, the council's executive vicepresident. "Better to assure the absence of influence, regardless of the amount of support."

The move is the latest attempt by a US body to limit the influence that industry has on decisions made by physicians and the council calls it "the biggest step" it has made to confront conflicts of interest (www.cmss.org /uploadedFiles/Site/CMSS_Policies /CMSS\%20Code\%20for\%20Interac tions \%20with\%20Companies\%204-19 -10.pdf).

"Physicians and patients count on medical societies to be authoritative, independent voices in science and medicine," stated Dr. Allen Lichter, chief executive officer of the American Society of Clinical Oncology and chair of the task force that developed the code, in a press release (www.cmss.org/Default TwoColumn.aspx?id=110). "By adopting this code, societies demonstrate their commitment to the highest level of ethical standards in their activities and to

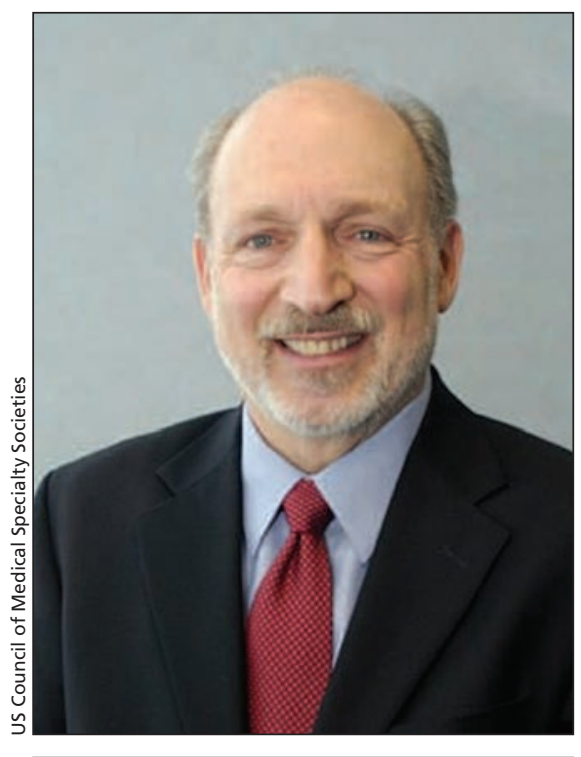

The goal is to eliminate industry influence, not industry support, says Dr. Norman Kahn, executive vice-president of the United States Council of Medical Specialty Societies

providing the best possible care for patients and populations.'

Under the code, member societies will be required to keep at "arms length" from industry by using written agreements for any transactions with companies, disclosing company support to the public, seeking multiple corporate sponsors where possible, and declining charitable donations if a donor expects to influence programming or advocacy positions.

As far as individual conflict of interest goes, there's only one directive in the code: a controversial requirement that top society leaders and journal editors divest themselves of all direct financial ties to industry.

That was the most challenging rule to get approved by the 30-person task force that developed the code, many of whom are key society leaders, Kahn says.

"Disclosure and management of conflict of interest is appropriate in most cases," he says. "[But] when a leader is standing up in front of Congress or the media or the public representing their profession, there shouldn't be any confusion as to who they represent."

Leaders may still provide uncompensated service to companies and can accept research support so long as grant money is paid to an institution or practice and not to the leaders themselves.

The code also requires that leaders and board members of societies disclose all relationships to industry, including employment and consulting arrangements, stock ownership, honoraria, research funding, expert testimony and gifts.

The code imposes no obligations on any of the 650000 US physicians who collectively belong to the 32 medical specialty societies that are members of the council.

"Our members are societies, not individual physicians," explains Kahn.

Nor does it obligate any current society leaders to drop their industry ties in a hurry. Any leader elected or appointed prior to their society signing onto the code can maintain existing financial relationships with companies for the duration of their term.

Thirteen member societies have already formally adopted the code, including heavy-hitters like the American Society of Clinical Oncology, the world's largest group of cancer specialists. The council hopes other members will adopt the code in coming months.

In addition to demands for disclosure, the code requires societies to ban company giveaways; to forbid industry influence over the awarding of grants and any resulting research, manuscripts, rights or royalties; to decline company funding for the development of medical guidelines, while ensuring that panelists developing those guidelines are free of industry ties; and to prevent companies from shadow-writing articles for society journals, and journals from publishing company ads next to articles about that company.

The council joins US medical schools in moving to tighten the noose on conflicts of interest. Recently, Har- 
vard moved to obligate professors and lecturers to disclose industry ties to students after a spate of protests and a US Senate investigation into accusations that three of the school's professors failed to properly report US \$4.2 million in drug-company funding.

As of February, about 35 US universities had created new policies to guide the relationship between academia and industry, according to the American Medical Student Association. (CMAJ 2010. DOI:10.1503/cmaj.109-3151)

Although there's widespread variation in the policies of Canadian medical schools, officials have argued low levels of abuse mitigate the need for restrictive policies on industry handouts (CMAJ
2008. DOI:10.1503/cmaj.081008). The Association of Faculties of Medicine of Canada and the Canadian Association for Medical Education are exploring the need for more restrictive guidelines (CMAJ 2008. DOI:10.1503/cmaj.08 1268). — Lauren Vogel, Ottawa, Ont.

DOI:10.1503/cmaj.109-3253 